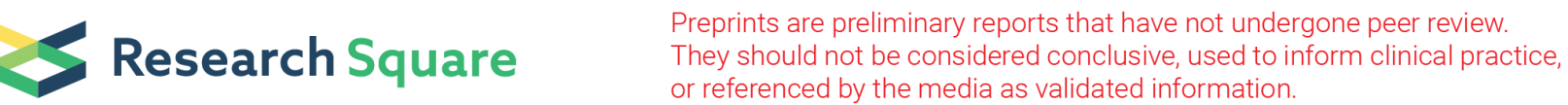

\section{Knowledge, Attitude, and Practices (KAP) of Diabetics towards Diabetes and Diabetic Retinopathy in Riyadh, Saudi Arabia: Cross-sectional study}

Abdulrahman Abdullah Al-Yahya

king saud university college of medicine

Alwaleed Mohammad Alsulaiman

King Saud University College of medicine

Abdulrahman Almizel

King saud university college of medicine

Abdulrahman Mohammed barri

King Saud University college of medicine

Fadwa Al Adel ( $\square$ ffaladel@pnu.edu.sa )

Princess Nourah bint Abdulrahman University College of Medicine

\section{Research article}

Keywords: DM, diabetes mellitus, DR, diabetic retinopathy, regular eye exam, primary care, diabetes awareness, knowledge, attitude and practice

Posted Date: May 6th, 2020

DOI: https://doi.org/10.21203/rs.2.20425/v2

License: (c) (i) This work is licensed under a Creative Commons Attribution 4.0 International License.

Read Full License

Version of Record: A version of this preprint was published at Clinical Ophthalmology on October 1st, 2020. See the published version at https://doi.org/10.2147/OPTH.S269524. 


\section{Abstract}

Objective : To identify the knowledge, attitude, and practices (KAP) of diabetic patients towards diabetes and diabetic retinopathy in Riyadh, Saudi Arabia.

Methods: This cross sectional study was conducted in 50 randomly selected primary care centers and two university hospitals in Riyadh, Saudi Arabia, between May and December 2018. Diabetic patients $\geq$ 18 years old were enrolled in the study. A validated KAP-45 questionnaire was used to assess the KAP levels of diabetics towards diabetes and diabetic retinopathy.

Results: A total of 313 participants were enrolled in the study. The majority were males $168(59.8 \%)$. The median age was $49 \pm 24$, and the median duration of diabetes was $8 \pm 11$ years. The average knowledge score for diabetes was good 10 . While, the average knowledge score for diabetic retinopathy was suboptimal 4.5. The average attitude scores for both diabetes and diabetic retinopathy were suboptimal 0 and 2 respectively. The average practice score for diabetes was good 5 while it was low 3 for diabetic retinopathy. The most common barrier to comply with regular follow up was inadequate knowledge about the importance of periodic eye exam $47.1 \%(107)$.

Conclusions: It is important to improve education and awareness of DM and diabetic retinopathy among diabetics, as it's essential for controlling the disease and reducing its complications, by improving patient compliance to treatment and follow up.

\section{Introduction}

Diabetes mellitus (DM) is a chronic metabolic disease related to insulin and is one of the most significant worldwide health problems. In 2014, the WHO estimated that globally, 422 million people were affected by DM.(1) This number is expected to rise to 592 million by 2035.(2) Alnozha et al. reported that DM prevalence in Saudi Arabia was 23.7\% in 2011, the second highest among Middle Eastern countries and the seventh highest worldwide according to the WHO ranking.(3) This number is expected to increase further in the upcoming years.

Diabetic retinopathy (DR) is one of many devastating ischemic complications of DM.(4) It is a silent, progressive disease that can lead to irreversible blindness. Studies estimate that $2 \%$ of diabetic patients will go blind within 15 years of diagnosis.(5) Nevertheless, the condition is responsible for $4.8 \%$ of blindness worldwide.(6) DR is common among Saudi diabetics. A prevalence of $36 \%$ was reported in AlMedina city, and 33\% in Al Ahsa region of Saudi Arabia.(7),(8) Studies found that high blood sugar, long duration of DM, and associated high blood pressure are major risk factors for the development of DR. Tight control of the blood sugar is highly effective in delaying the onset of and preventing the progression of DR. Nevertheless, sudden tight control of blood sugar after a long period of poor control, might initially worsen the retinopathy.(9) Almost all patients are asymptomatic in the early stages of DR, but RCTs 
found that early screening and intervention could prevent visual loss in patients with DR by $57 \%$.(9) Therefore, early detection and treatment are vital to prevent visual loss.(10)

Awareness and proper knowledge of this highly prevalent disease is crucial to enhance early detection and proper intervention.(9) Patients with higher-than-average knowledge of the condition were found to have a positive attitude and a good practice pattern, which gave them the advantage of earlier presentation in their course of illness. In addition, patients with a lack of awareness showed poorer control of DR risk factors.(11) Therefore, the aim of this study was to identify the Knowledge, Attitude, and Practices (KAP) of diabetics towards diabetes and diabetic retinopathy in Riyadh City, Saudi Arabia.

\section{Methods}

\section{Study Settings:}

Approval from the institutional review board was obtained from King Saud University (KSU) prior to the start of the study. Consent was received from all patients via a consent form to allow for inclusion of their non-identifiable information in the study. This was a cross sectional study of type 1 and 2 adult diabetic patients, $\geq 18$ years old, conducted between May and December 2018 in Riyadh, Saudi Arabia. A list of all 418 primary care centers in the Riyadh region was drawn up from the Ministry of Health website. The list was further filtered to include only centers inside Riyadh City. A random number table was used to select 50 primary care centers from each region of Riyadh City (West, East, Center, North, South). In addition, two university hospitals affiliated with KSU in Riyadh were included to compare patients in two different settings, university hospitals versus primary care centers.

\section{Sample Size and Sampling Technique}

The sample size was calculated using Roasoft software. The single proportion sample size formulae was used, with a precision of $5 \%$, and a confidence interval of $95 \%$. The percentage of diabetic patients with significant knowledge was assumed to be $85 \%$. Participants were selected by a systematic random sampling method. All patients that attended clinics in the selected centers during the period of the study were included.

\section{Questionnaire}

The demographic variables included in the study were: gender, age, marital status, educational level, and monthly income. The Knowledge, Attitude, and Practice -45 points (KAP-45) questionnaire was formulated by Sheeja Susan John et al.(11) Permission to use the KAP-45 questionnaire was granted 
after communication with its main authors. The KAP-45 questionnaire is divided into: 13 questions in the knowledge section (five to assess patients' knowledge of diabetes and eight to assess patients' knowledge of diabetic retinopathy), eight questions in the attitude section (four to assess patients' attitude towards diabetes and four to assess patients' attitude towards diabetic retinopathy), and 24 questions in the practice section (six to assess patients' practice patterns regarding diabetes and 18 to assess patients' practice patterns regarding diabetic retinopathy). Some of the questions in the knowledge and practice sections of the questionnaire were constructed as open-ended questions, whereas questions in the attitude section were framed as statements.

Participants were categorized as having "sufficient knowledge" if they answered nine or more of the "must know" questions regarding diabetes and if they answered five or more of the "must know" questions regarding diabetic retinopathy. In addition, participants were categorized as having "good practice" if they answered four or more of the "must do" questions regarding diabetes and if they answered four or more of the "must do" questions regarding diabetic retinopathy. In the attitude section of the questionnaire, participants were categorized as having a "positive attitude" when they scored three or higher in statements that were indicative of a positive attitude towards diabetes and diabetic retinopathy.

The KAP-45 questionnaire was validated by a face validity method into Arabic. Two bilingual ArabicEnglish speakers translated the original English version of the questionnaire into Arabic, then an expert committee was formed to review and culturally adapt the KAP-45 questionnaire. Finally, a feedback from the pilot study, initially done, was taken into consideration to finalize the Arabic version of KAP-45 questionnaire.

\section{Statistical Analysis}

The analysis was performed using SPSS version 22.0 software (SPSS Inc., Chicago, IL, U.S.), to calculate the demographics and responses to the questionnaire. Categorical data were expressed as frequencies and percentages. Continuous data were expressed using medians and interquartile ranges (IQ) or means and standard deviations (SD), as indicated. Chi-Square and Fisher's exact tests were used to compare between the variables, A P-value of less than 0.05 was considered statistically significant for all analysis. Construct validity was done by exploratory factor analysis using principal component analysis extraction and Varimax rotation after conducting Kaiser-Meyer-Olkin Measure and Bartlett's test of sphericity of Sampling Adequacy Test on KAP questionnaire. Only factors equivalent or greater to 1 were included, items were deleted if they did not exceed a 0.4 factor loading cut off. No cross loading was detected.

\section{Result}

A total of 313 participants were enrolled in the study. 59.8\% (168) were males and $40.2 \%$ (125) were females. Most of our study respondents $64.2 \%$ (194) were between the age of $30-60$. Among them, $64 \%$ 
(199) were married. Of the 313 recruited, $12.3 \%$ (38) were illiterate and $45.4 \%$ (141) had at least a bachelor's degree. The median duration of diabetes was $8 \pm 11$ years and $78 \%$ (244) had a positive family history of diabetes.(Table 1)

The median knowledge score for diabetes was 10 (good knowledge range 9-17) and 4.5 (good knowledge range 5-11) for diabetic retinopathy. Most of the participants $95.2 \%$ (295) knew that high sugar levels could be detected by blood testing. However, only $25.2 \%$ (78) knew that high sugar levels could be detected in urine as well. Surprisingly, only half of the participants knew that diabetes could lead to visual problems, 53\% (166) of participants knew that the condition affects the retina, and $40.6 \%$ (127) knew that it can cause cataracts. Only a few patients $10.2 \%$ (32) knew that DM increases the risk of infections. Higher educational levels and younger age were significantly associated with good levels of knowledge of DM $(p<0.0001)$ and $(p<0.049)$ respectively. (Table 2$)$ Meanwhile, good knowledge of DM and DR were significantly associated with higher monthly income $(p<0.0001)$ and $(p<0.015)$ respectively. (Table 3$)$ There was no significant association between gender, the duration of $D M$, and the level knowledge of DM and DR $(p<0.386),(p<0.711),(p<0.441)$ and $(p<0.447)$ respectively. $($ Table 2,3$)$

Only 237 of the total 313 participants responded to the question regarding the effect of poor glucose control on worsening DR. Fifty four $22.8 \%$ believed that poor glucose control is a factor which can worsen diabetic retinopathy. While, more than half of the respondents $54.4 \%$ (129) believed that kidney problems could worsen diabetic retinopathy.

Out of 305 respondents, $82.6 \%$ (252) chose the eye as the first organ that would be affected by DM, followed by the kidneys $54.4 \%$ (129). Interestingly, $54.9 \%$ (134) believed that they need a fundus examination once every five years, while only $28.7 \%(70)$ believed that they need it once every year.

The median attitude score for diabetes was 0 (good attitude range 3-4) and 2 (good attitude range 3-4) for diabetic retinopathy. Surprisingly, out of 279 respondents, $58.1 \%$ (162) thought it was fine not to comply with diabetic diet occasionally. While, out of 280 respondents, $23.9 \%$ (67) thought it was fine to forget to take their medications. $62.9 \%$ (175) did not believe it was important to check their eyes regularly, as long as they were asymptomatic. However, $75.8 \%$ (210) believed that they should follow up with an ophthalmologist even if their blood sugar was under control. The level of attitude toward DR was significantly lower in respondents attending a primary care clinic than respondents in a university hospital $(p<0.0001)$. (Table 3) 
The median practice score for diabetes was 5 (good practice range 4-5) and 3 (good practice range 4-5) for diabetic retinopathy. Most of the respondents, $60.4 \%$ (166), follow up regularly to have their funduscopic screening examination. However, only $33.1 \%$ (92) of the respondents continue to follow up despite a normal initial funduscopic screening examination. The most common reasons not to comply with regular follow-ups were: "they thought it was not important" followed by "lack of family support" $47.1 \%$ (107) and $41.4 \%$ (94), respectively. Out of 74 respondents, $32.4 \%$ (24) did not attend their annual funduscopic screening visits because they had good vision and did not feel the need for an annual checkup. High level of education of respondents was significantly associated with poor practice of DR $(p<0.013)$. (Table 2) There was no significant association between age, gender and the level practice of DM and DR. (Table 2,3)

\section{Discussion}

Diabetes is a worldwide growing burden.(2) Therefore, the incidence of diabetic retinopathy is also expected to increase. This risk can be reduced by effective screenings and tight control of blood sugar.(4) Lack of awareness in the community regarding diabetes and diabetic retinopathy greatly impacts delivery of care.(12) In our study, our goal was to identify the Knowledge, Attitude, and Practice (KAP) of diabetics in Riyadh, Saudi Arabia, towards diabetes and diabetic retinopathy and correlate it with sociodemographic factors. As well as, to identify the barriers of poor compliance in both follow up and treatment.

Among our participants, the average knowledge score of DM was good which is consistent with another study conducted by Mohammed Zibran et al in Fiji, that reported a good knowledge level with a mean knowledge score of 23.3 out of 30 (SD \pm 3.25 ).(13) In contrast, Sheeja Susan John et al, in India, reported that $58 \%$ of their sample had poor knowledge. Although our participant showed good DM knowledge, their knowledge regarding DR was suboptimal. In our study, participants knew that they needed screening for DR, However they didn't know how frequently they should do it. In Jordan, only $20.7 \%$ said that eye examination should be done annually.(14) In Turkey, only $41.9 \%$ stated that annual eye examination was necessary.(15) On the other hand, the majority of our participants (82.6\%) knew that DM can affect different structures of the eyes, which was consistent with another local study done in Al Jawf region in Saudi Arabia, where $75.62 \%$ of their respondents knew about ocular complications of DM.(16) Other studies in the Middle Eastern region were conducted in Jordan and Oman which revealed that $88.2 \%$ and $72 \%$ knew that DR is a complication of DM respectively.(14)(17) In India, a similar study revealed that only $27 \%$ of respondents knew about DM effect on the eye.(18) Therefore, we suggest that patients newly diagnosed with DM should be referred to a diabetes educator, to educate them about the possible ocular complications, how to prevent them, and the importance of regular ocular screening and follow up. 
It is well known that the prevalence of DR is dependent on glycemic control (19) as well as blood pressure control.(20) However, only $22.8 \%$ of our respondents believed that poor glycemic control was an important factor that worsens diabetic retinopathy. Hypertension is commonly associated with DM as part of a metabolic syndrome. High blood pressure increases the risk of both the development and progression of DR.(20) Studies have shown that tight control of blood pressure in diabetic and hypertensive patients can delay the onset of DR.(20) Unfortunately, a small number of respondents in our study, knew that uncontrolled blood pressure worsens DR. These two reasons maybe major contributors to the high prevalence of DR in diabetic patients in Saudi Arabia.(21)

The diabetic retinopathy attitude score in our sample was poor. In contrast, Sheeja Susan John et al, reported that $61.4 \%$ of their sample had a good attitude score towards DR.(11) Most of our respondents agreed on the importance of follow up with an ophthalmologist regardless of their blood sugar level. However, the majority of them do not believe it is important to follow up when their vision is good $(62.9 \%)$. This is believed to be one of the important barriers that limit our sample to seek annual eye examinations. Similarly, Sheeja Susan John et al in India reported that $30.56 \%$ of their sample did not believe in the importance of annual eye examination. (11) These Findings emphasize the importance of educating patients about the nature of the disease, which can affect the eyes silently, and the importance of regular ocular screening and follow up.

The overall score for DR practice was below the acceptable range. This can be explained by, the low level of knowledge and attitude in our sample. More than half of our sample (60.4\%), follow up regularly for a funduscopic screening examination. Ali Raza et al(22) reported a similar finding, $73 \%$ of his sample had regular funduscopic screening examination. However, our results are slightly lower than a previous local study done in Al Jawf region in Saudi Arabia, which had a much higher percentage (95\%) of follow up. (16) This could be due to the fact that a notable number of our respondents do not continue to follow up, once their eyes screening is normal. This reflects people's lack of knowledge about the silent nature of the disease. Although patients suffering from DM might have a good knowledge about the disease effects on the eyes, that doesn't necessarily mean that they will have good practice. Funatsu et al (23) reported that while more than $98 \%$ of patients were aware of diabetic eye disease, only $69.5 \%$ of the patients visited the ophthalmologist for periodic eye examinations. The same finding has been described by alzahrani et al (24) which revealed that $82.6 \%$ of his sample were aware of DM complications in their eyes, however, only $65 \%$ had their eye checkups regularly. This could be due to many reasons other than lack of knowledge, such as, lack of time, transportation difficulties, and lack of family support. So in addition to patient education, we suggest having the fundoscopic screening examination for diabetic patients done at the same time and place in their regular diabetes follow up.

\section{Conclusions}


Our study does not constitute a representative sample of Saudi Arabia. However, it gives a general picture of the awareness, attitude and practices of diabetics regarding diabetes and diabetic retinopathy in the country. These findings highlight the importance of diabetic education as awareness is critical for controlling diabetes and reducing the incidence of diabetes related complications, especially diabetic retinopathy where patient education, awareness of the nature of the disease, and importance of regular screening and follow up will probably increase patient compliance to regular ocular screening which will help in controlling the disease and improving its outcome.

\section{List Of Abbreviations}

DR "diabetic retinopathy" DM "diabetes mellitus" KAP "knowledge attitude and practice" SD "standard deviation"

\section{Declaration}

\section{Ethical approval and consent to participate}

Approval from King Saud University institutional board headed by the research committee was obtained prior to the study and all participants were consented.

\section{Consent for publication}

All participants were given consent form. The informed consent was clear and indicated the purpose of this study and the right of the participant to withdraw at any time without any obligation on towards the study team.

\section{Availability of data and material}

The datasets used and/or analysed during the current study are available from the corresponding author on reasonable request.

\section{Competing interests}

Not applicable

\section{Funding}

Not applicable

\section{Author's contribution}

FA helped in research supervision, Data management and analysis, progress report, final report and manuscript writing. 
AA1 helped in review of literature, study design, progress report, data collection, data management and analysis, final report and manuscript writing

AA3 helped in review of literature, study design, progress report, data collection, data management and analysis, final report and manuscript writing

AA2 helped in review of literature, study design, progress report, data collection, data management and analysis, final report and manuscript writing

AB helped in review of literature, study design, progress report, data management and analysis, final report and manuscript writing

All authors have read and approved the manuscript. All author have agreed to be personally accountable for author's own contribution even the ones in which author was not personally involve.

\section{Acknowledgement}

The authors thank the professionals of the centers that assisted in data collection and all the participating patients.

\section{Author information}

Fadwa Al Adel, Department of Ophthalmology, College of Medicine, Princess Nourah bint Abdulrahman University, Riyadh, Saudi Arabia. Initals : FA

Abdulrahman Mohammed Barri, intern in King Saud University college of medicine, Riyadh, Saudi Arabia . Initials : $A B$

Abdulrahman Al-Yahya, intern in King Saud University college of medicine, Riyadh, Saudi Arabia. Initials: AA1

Abdulrahman Almizel, intern in King Saud University college of medicine, Riyadh, Saudi Arabia. Initials : AA2

Alwaleed Alsulaiman, intern in King Saud University college of medicine, Riyadh, Saudi Arabia. Initials: AA3

\section{References}

1. World Health Organization. Global Report on Diabetes. Isbn. 2016;

2. Guariguata L, Whiting DR, Hambleton I, Beagley J, Linnenkamp U, Shaw JE. Global estimates of diabetes prevalence for 2013 and projections for 2035. Diabetes Res Clin Pract. 2014;

3. Al-Nozha MM, Al-Maatouq MA, Al-Mazrou YY, Al-Harthi SS, Arafah MR, Khalil MZ, et al. Diabetes mellitus in Saudi Arabia. Saudi Med J. 2004; 
4. Tarr JM, Kaul K, Chopra M, Kohner EM, Chibber R. Pathophysiology of Diabetic Retinopathy. ISRN Ophthalmol. 2013;

5. World Health Organization. Prevention of blindness from diabetes mellitus. Geneva WHO. 2005;

6. Memon MS, Shaikh SA, Shaikh AR, Fahim MF, Mumtaz SN, Ahmed N. An assessment of knowledge, attitude and practices (KAP) towards diabetes and diabetic retinopathy in a suburban town of Karachi. Pakistan J Med Sci. 2015;

7. Khan A, Wiseberg J, Lateef ZA, Khan S. Prevalence and determinants of diabetic retinopathy in Al Hasa region of Saudi Arabia: primary health care centre based cross-sectional survey, 2007-2009. Middle East Afr J Ophthalmol. 2010;

8. El-Bab MF, Shawky N, Al-Sisi A, Akhtar M. Retinopathy and risk factors in diabetic patients from AlMadinah Al-Munawarah in the Kingdom of Saudi Arabia. Clin Ophthalmol. 2012;

9. Ting DSW, Cheung GCM, Wong TY. Diabetic retinopathy: global prevalence, major risk factors, screening practices and public health challenges: a review. Clinical and Experimental Ophthalmology. 2016.

10. Huang OS, Zheng Y, Tay WT, Chiang PPC, Lamoureux EL, Wong TY. Lack of awareness of common eye conditions in the community. Ophthalmic Epidemiol. 2013;

11. Srinivasan NK, John D, Rebekah G, Kujur ES, Paul P, John SS. Diabetes and diabetic retinopathy: Knowledge, Attitude, Practice (KAP) among diabetic patients in a tertiary eye care centre. J Clin Diagnostic Res. 2017;

12. Nirmalan PK, Katz J, Robin AL, Krishnadas R, Ramakrishnan R, Thulasiraj RD, et al. Utilisation of eye care services in rural south India: The Aravind Comprehensive Eye Survey. $\mathrm{Br} \mathrm{J}$ Ophthalmol. 2004;

13. Zibran MA, Mohammadnezhad M. Determinants of knowledge, attitude and practice in patients with both type 2 diabetes and chronic kidney disease in Fiji. F1000Research. 2019;

14. Bakkar MM, Haddad MF, Gammoh YS. Awareness of diabetic retinopathy among patients with type 2 diabetes mellitus in Jordan. Diabetes, Metab Syndr Obes Targets Ther. 2017;

15. Çetin EN, Zencir M, Fenkçi S, Akin F, Yildirim C. Assessment of awareness of diabetic retinopathy and utilization of eye care services among Turkish diabetic patients. Prim Care Diabetes. 2013;

16. Al Zarea BK. Knowledge, attitude and practice of diabetic retinopathy amongst the diabetic patients of of AlJouf and Hail Province of Saudi Arabia. J Clin Diagnostic Res. 2016;

17. Khandekar R, Al Harby S, Al Harthy H, Al Lawatti J. Knowledge, attitude and practice regarding eye complications and care among Omani persons with diabetes - A cross sectional study. Oman J Ophthalmol. 2010;

18. Hussain R, Rajesh B, Giridhar A, Gopalakrishnan M, Sadasivan S, James J, et al. Knowledge and awareness about diabetes mellitus and diabetic retinopathy in suburban population of a South Indian state and its practice among the patients with diabetes mellitus: A population-based study. Indian J Ophthalmol. 2016; 
19. Stratton IM, Kohner EM, Aldington SJ, Turner RC, Holman RR, Manley SE, et al. UKPDS 50: Risk factors for incidence and progression of retinopathy in Type II diabetes over 6 years from diagnosis. Diabetologia. 2001;

20. Pescosolido N, Rusciano D. Diabetic Retinopathy and Hypertension. jscimed Cent. 2015;

21. Al-Rubeaan K, Abu El-Asrar AM, Youssef AM, Subhani SN, Ahmad NA, Al-Sharqawi AH, et al. Diabetic retinopathy and its risk factors in a society with a type 2 diabetes epidemic: A Saudi National Diabetes Registry-based study. Acta Ophthalmol. 2015;

22. Raza A, Khan I, Sami H, Ejaz A, Ahmed Z. "Diabetic retinopathy - knowledge, attitude and practices (KAP) in diabetic patients admitted in Tertiary Care Centers of Peshawar - Khyber Pakhtunkhwa". Prof Med J. 2019;

23. Funatsu H, Hori S, Shimizu E, Nakamura S. Questionnaire survey on periodic ocular examination in Japanese diabetic patients. Am J Ophthalmol. 2003;

24. Alzahrani SH, Bakarman MA, Alqahtani SM, Alqahtani MS, Butt NS, Salawati EM, et al. Awareness of diabetic retinopathy among people with diabetes in Jeddah, Saudi Arabia. Ther Adv Endocrinol Metab. 2018;

\section{Tables}




\begin{tabular}{|c|c|c|}
\hline \multicolumn{2}{|l|}{ variable } & Frequency(\%) \\
\hline \multirow[t]{3}{*}{ Age $(n=302)$} & $<30$ & $55(18.2 \%)$ \\
\hline & $30-60$ & $194(64.2 \%)$ \\
\hline & $>60$ & $53(17.5 \%)$ \\
\hline \multirow[t]{2}{*}{ Gender } & Male & $168(59.8 \%)$ \\
\hline & Female & $125(40.2 \%)$ \\
\hline \multirow[t]{4}{*}{ Marital status $(n=311)$} & Sinlge & $67(21.5 \%)$ \\
\hline & Married & $199(64 \%)$ \\
\hline & Widow & $32(10.3 \%)$ \\
\hline & Divorced & $13(4.2 \%)$ \\
\hline \multirow[t]{6}{*}{ Educational level $(n=310)$} & Illiterate & $38(12.3 \%)$ \\
\hline & Primary & $31(10 \%)$ \\
\hline & Secondary & $30(9.7 \%)$ \\
\hline & High school & $70(22.6 \%)$ \\
\hline & Collage & $104(33.5 \%)$ \\
\hline & Post araduate & $37(11.9 \%)$ \\
\hline \multirow[t]{5}{*}{ Family monthly income $(\mathrm{n}=289)$} & $<5 \mathrm{~K}$ & $62(21.5 \%)$ \\
\hline & $5-10 K$ & $66(22.8 \%)$ \\
\hline & $10-15 \mathrm{~K}$ & $76(26.3 \%)$ \\
\hline & $15-20 \mathrm{~K}$ & $50(17.3 \%)$ \\
\hline & $>20 \mathrm{~K}$ & $35(12.1 \%)$ \\
\hline \multicolumn{2}{|l|}{ Family member has DM $(n=313)$} & $244(78 \%)$ \\
\hline \multirow[t]{3}{*}{ Duration of DM $(n=308)$} & $<=10$ years & $200(64.9 \%)$ \\
\hline & $<=20$ years & $83(26.9 \%)$ \\
\hline & $>20$ years & $25(8.1 \%)$ \\
\hline
\end{tabular}




\begin{tabular}{|c|c|c|c|c|c|c|c|c|c|c|}
\hline \multirow{2}{*}{\multicolumn{2}{|c|}{ 2: Diabetes KAP }} & \multicolumn{2}{|c|}{ Knowledge $(n=304)$} & \multirow[t]{2}{*}{ P-value } & \multicolumn{2}{|c|}{ Attitude $(n=277)$} & \multirow{2}{*}{$\begin{array}{c}\text { P- } \\
\text { value }\end{array}$} & \multicolumn{2}{|c|}{ Practice $(n=214)$} & \multirow{2}{*}{$\begin{array}{c}\mathrm{P}- \\
\text { value }\end{array}$} \\
\hline & & Good & Poor & & Good & Poor & & Good & Poor & \\
\hline & Male & $68(56.2 \%)$ & $53(43.8 \%)$ & \multirow[t]{2}{*}{0.386} & 0 & $109(100 \%)$ & \multirow[t]{2}{*}{0.519} & $29(37.2 \%)$ & $49(62.8 \%)$ & \multirow[t]{2}{*}{0.108} \\
\hline & Female & $92(51.1 \%)$ & $88(48.9 \%)$ & & $2(1.2 \%)$ & $163(98.8 \%)$ & & $66(48.5 \%)$ & $70(51.5 \%)$ & \\
\hline \multirow[t]{10}{*}{ us } & Single & $42(64.6 \%)$ & $23(35.4 \%)$ & \multirow[t]{4}{*}{0.165} & 0 & $61(100 \%)$ & \multirow[t]{4}{*}{0.639} & $21(38.9 . \%)$ & $33(61.1 \%)$ & \multirow[t]{4}{*}{0.737} \\
\hline & Married & $95(48.7 \%)$ & $100(51.3 \%)$ & & $3(1.7 \%)$ & $173(98.3 \%)$ & & $60(47.6 \%)$ & $66(52.4 \%)$ & \\
\hline & Widow & $16(53.3 \%)$ & $14(46.7 \%)$ & & 0 & $25(100 \%)$ & & $10(43.5 \%)$ & $13(56.5 \%)$ & \\
\hline & Divorced & $7(58.3 \%)$ & $5(41.7 \%)$ & & 0 & $12(100 \%)$ & & $4(50 \%)$ & $4(50 \%)$ & \\
\hline & Illiterate & $12(32.4 \%)$ & $25(67.6 \%)$ & \multirow[t]{6}{*}{$<0.0001$} & 0 & $32(100 \%)$ & \multirow[t]{6}{*}{0.668} & $16(57.1 \%)$ & $12(42.9 \%)$ & \multirow[t]{6}{*}{0.013} \\
\hline & Primary & $14(46.7 \%)$ & $16(53.3 \%)$ & & $1(4 \%)$ & $24(96 \%)$ & & $10(40 \%)$ & $15(60 \%)$ & \\
\hline & Secondary & $12(40 \%)$ & $18(60 \%)$ & & 0 & $28(100 \%)$ & & $10(52.6 \%)$ & $9(47.4 \%)$ & \\
\hline & High school & $30(44.8 \%)$ & $37(55.2 \%)$ & & $1(1.7 \%)$ & $58(98.3 \%)$ & & $27(57.4 \%)$ & $20(42.6 \%)$ & \\
\hline & Collage & $62(60.8 \%)$ & $40(39.2 \%)$ & & $1(1.1 \%)$ & $93(98.9 \%)$ & & $27(38.6 \%)$ & $43(61.4 \%)$ & \\
\hline & Post graduate & $31(83.8 \%)$ & $6(16.2 \%)$ & & 0 & $36(100 \%)$ & & $3(14.3 \%)$ & 18(85.7\%) & \\
\hline \multirow[t]{5}{*}{ hly } & $<5 \mathrm{~K}$ & $20(33.9 \%)$ & $39(66.1 \%)$ & $<0.0001$ & $1(1.9 \%)$ & $51(98.1 \%)$ & 0.495 & $19(43.2 \%)$ & $25(56.8 \%)$ & 0.065 \\
\hline & $5-10 \mathrm{~K}$ & $33(50.8 \%)$ & $32(49.2 \%)$ & & 0 & $58(100 \%)$ & & $24(54.5 \%)$ & $20(45.5 \%)$ & \\
\hline & $10-15 K$ & $45(60.8 \%)$ & $29(39.2 \%)$ & & $2(2.8 \%)$ & $69(97.2 \%)$ & & $28(54.9 \%)$ & $23(45.1 \%)$ & \\
\hline & $15-20 \mathrm{~K}$ & $33(67.3 \%)$ & $16(32.7 \%)$ & & 0 & $46(100 \%)$ & & $9(29 \%)$ & $22(71 \%)$ & \\
\hline & $>20 \mathrm{~K}$ & $26(76.5 \%)$ & $8(23.5 \%)$ & & 0 & $34(100 \%)$ & & $7(30.4 \%)$ & $16(69.6 \%)$ & \\
\hline er has & $\mathrm{DM}$ & $128(53.8 \%)$ & $110(46.2 \%)$ & 0.666 & $2(0.9 \%)$ & $218(99.1 \%)$ & 0.495 & $71(42 \%)$ & $98(58 \%)$ & 0.136 \\
\hline ow up & university & $53(52 \%)$ & $49(48 \%)$ & 0.804 & $2(2.2 \%)$ & $91(79.8 \%)$ & 0.222 & $24(48 \%)$ & $26(52 \%)$ & 0.558 \\
\hline & $\begin{array}{l}\text { Primary } \\
\text { care }\end{array}$ & 108(53.5\%) & $94(46.5 \%)$ & & $1(0.5 \%)$ & 183(99.5\%) & & $71(43.3 \%)$ & $93(56.7 \%)$ & \\
\hline$!$ & $<30$ & $38(69.1 \%)$ & $17(30.9 \%)$ & 0.049 & 0 & $49(100 \%)$ & 0.200 & $16(39 \%)$ & $25(61 \%)$ & 0.380 \\
\hline & $30-60$ & $95(50.5 \%)$ & $93(49.5 \%)$ & & $1(0.6 \%)$ & $176(99.4 \%)$ & & $63(47.4 \%)$ & $70(52.6 \%)$ & \\
\hline & $>60$ & $26(52 \%)$ & $24(48 \%)$ & & $1(2.4 \%)$ & $41(97.6 \%)$ & & $11(35.5 \%)$ & $20(64.5 \%)$ & \\
\hline M & $<=10$ & $102(52.6 \%)$ & $92(47.4 \%)$ & 0.441 & $1(0.6 \%)$ & 178(99.4\%) & 0.192 & $66(45.8 \%)$ & $78(54.2 \%)$ & 0.565 \\
\hline & $<=20$ & $47(58 \%)$ & $34(42 \%)$ & & 0 & $72(100 \%)$ & & $25(46.3 \%)$ & $29(53.7 \%)$ & \\
\hline & $>20$ & $11(44 \%)$ & $14(56 \%)$ & & $1(4.8 \%)$ & $20(95.2 \%)$ & & $4(30.8 \%)$ & $9(69.2 \%)$ & \\
\hline
\end{tabular}




\begin{tabular}{|c|c|c|c|c|c|c|c|c|c|c|}
\hline \multirow{2}{*}{\multicolumn{2}{|c|}{ Retinopathy KAP }} & \multicolumn{2}{|c|}{ Knowledge $(n=177)$} & \multirow{2}{*}{$\begin{array}{c}\mathrm{P} \text { - } \\
\text { value }\end{array}$} & \multicolumn{2}{|c|}{ Attitude $(n=277)$} & \multirow[t]{2}{*}{ P-value } & \multicolumn{2}{|c|}{ Practice $(n=68)$} & \multirow{2}{*}{$\begin{array}{c}\mathrm{P}- \\
\text { value }\end{array}$} \\
\hline & & \multirow{2}{*}{$\frac{\text { Good }}{36(48.6 \%)}$} & \multirow{2}{*}{$\begin{array}{c}\text { Poor } \\
38(51.4 \%)\end{array}$} & & Good & Poor & & Good & Poor & \\
\hline & Male & & & \multirow[t]{2}{*}{0.711} & $51(47.2 \%)$ & $57(52.8 \%)$ & \multirow[t]{2}{*}{$<0.025$} & $11(40.7 \%)$ & $16(59.3 \%)$ & \multirow[t]{2}{*}{0.364} \\
\hline & Female & $52(51.5 \%)$ & $49(48.5 \%)$ & & $56(33.7 \%)$ & $110(66.3 \%)$ & & $12(30 \%)$ & $28(70 \%)$ & \\
\hline \multirow[t]{4}{*}{ us } & Sinlge & $26(60.5 \%)$ & $17(39.5 \%)$ & \multirow[t]{4}{*}{0.353} & $17(27.9 \%)$ & $44(72.1 \%)$ & \multirow[t]{4}{*}{0.095} & $2(20 \%)$ & $8(80 \%)$ & \multirow[t]{4}{*}{0.519} \\
\hline & Married & $49(45.4 \%)$ & $59(54.6 \%)$ & & $79(44.9 \%)$ & $97(55.1 \%)$ & & $19(38 \%)$ & $31(62 \%)$ & \\
\hline & Widow & $8(50 \%)$ & $8(50 \%)$ & & $8(32 \%)$ & $17(68 \%)$ & & $1(16.7 \%)$ & $5(83.3 \%)$ & \\
\hline & Divorced & $3(37.5 \%)$ & $5(62.5 \%)$ & & $4(33.3 \%)$ & $8(66.7 \%)$ & & $1(50 \%)$ & $1(50 \%)$ & \\
\hline \multirow[t]{6}{*}{ level } & Illiterate & $7(36.8 \%)$ & $12(63.2 \%)$ & \multirow[t]{6}{*}{0.268} & $11(34.4 \%)$ & $21(65.6 \%)$ & \multirow[t]{6}{*}{0.847} & $3(50 \%)$ & $3(50 \%)$ & \multirow[t]{6}{*}{0.328} \\
\hline & Primary & $5(35.7 \%)$ & $9(64.3 \%)$ & & $8(32 \%)$ & $17(68 \%)$ & & $1(16.7 \%)$ & $5(83.3 \%)$ & \\
\hline & Secondary & $7(53.8 \%)$ & $6(46.2 \%)$ & & $12(42.9 \%)$ & $16(57.1 \%)$ & & $4(57.1 \%)$ & $3(42.9 \%)$ & \\
\hline & $\begin{array}{l}\text { High } \\
\text { school }\end{array}$ & $14(41.2 \%)$ & $20(58.8 \%)$ & & $24(42.1 \%)$ & $33(57.9 \%)$ & & $2(15.4 \%)$ & $11(84.6 \%)$ & \\
\hline & Collage & $37(54.4 \%)$ & $31(45.6 \%)$ & & $36(37.1 \%)$ & $61(62.9 \%)$ & & $8(33.3 \%)$ & $16(66.7 \%)$ & \\
\hline & $\begin{array}{l}\text { Post } \\
\text { graduate }\end{array}$ & $18(64.3 \%)$ & $10(35.7 \%)$ & & $16(45.7 \%)$ & $19(54.3 \%)$ & & $5(45.5 \%)$ & $6(54.5 \%)$ & \\
\hline \multirow[t]{5}{*}{ :hly } & $<5 \mathrm{~K}$ & $12(41.4 \%)$ & $17(58.6 \%)$ & \multirow[t]{5}{*}{0.015} & $23(44.2 \%)$ & $29(55.8 \%)$ & \multirow[t]{5}{*}{0.792} & $3(23.1 \%)$ & $10(76.9 \%)$ & \multirow[t]{5}{*}{0.121} \\
\hline & $5-10 K$ & $14(35.9 \%)$ & $25(64.1 \%)$ & & $22(37.9 \%)$ & $36(62.1 \%)$ & & $7(63.6 \%)$ & $4(36.4 \%)$ & \\
\hline & $10-15 \mathrm{~K}$ & $18(40 \%)$ & $27(60 \%)$ & & $29(40.8 \%)$ & $42(59.2 \%)$ & & $7(30.4 \%)$ & $16(69.6 \%)$ & \\
\hline & $15-20 \mathrm{~K}$ & $19(67.9 \%)$ & $9(32.1 \%)$ & & $16(34.8 \%)$ & $30(65.2 \%)$ & & $1(8.3 \%)$ & $11(91.7 \%)$ & \\
\hline & $>20 \mathrm{~K}$ & $17(68 \%)$ & $8(32 \%)$ & & $16(47.1 \%)$ & $18(52.9 \%)$ & & $5(55.6 \%)$ & $4(44.4 \%)$ & \\
\hline \multicolumn{2}{|c|}{ er has DM $(n=)$} & $74(52.1 \%)$ & $68(47.9 \%)$ & 0.252 & $80(36.5 \%)$ & $139(63.5 \%)$ & 0.135 & $15(28.8 \%)$ & $37(71.2 \%)$ & 0.78 \\
\hline \multirow[t]{5}{*}{ ow up } & university & $28(50.9 \%)$ & $27(49.1 \%)$ & \multirow[t]{2}{*}{0.831} & $56(61.5 \%)$ & $35(38.5)$ & \multirow[t]{2}{*}{$<0.0001$} & $14(34.1 \%)$ & $27(65.9 \%)$ & \multirow[t]{2}{*}{0.945} \\
\hline & $\begin{array}{l}\text { Primary } \\
\text { care }\end{array}$ & $60(49.2 \%)$ & $62(50.8 \%)$ & & $52(28 \%)$ & $134(72 \%)$ & & $9(33.3 \%)$ & $18(66.7 \%)$ & \\
\hline & $<30$ & $22(62.9 \%)$ & $13(37.1 \%)$ & \multirow[t]{3}{*}{0.084} & $16(39 \%)$ & $25(61 \%)$ & 0.439 & $2(22.2 \%)$ & $7(77.8 \%)$ & 0.747 \\
\hline & $30-60$ & $57(50.9 \%)$ & $55(49.1 \%)$ & & $74(42 \%)$ & $102(58 \%)$ & & $17(36.2 \%)$ & $30(63.8 \%)$ & \\
\hline & $>60$ & $8(33.3 \%)$ & $16(66.67 \%)$ & & $17(40.5 \%)$ & $25(59.5 \%)$ & & $3(30 \%)$ & $7(70 \%)$ & \\
\hline JM & $<=10$ & $60(53.6 \%)$ & $52(46.4 \%)$ & 0.447 & $68(38.2 \%)$ & $110(61.8 \%)$ & 0.330 & $14(32.6 \%)$ & $29(67.4 \%)$ & 1 \\
\hline & $<=20$ & $20(42.6 \%)$ & $27(57.4 \%)$ & & $32(44.4 \%)$ & $40(55.6 \%)$ & & $7(36.8 \%)$ & $12(63.2 \%)$ & \\
\hline & $>20$ & $7(50 \%)$ & $7(50 \%)$ & & $6(27.3 \%)$ & $16(72.7 \%)$ & & $1(25 \%)$ & $3(75 \%)$ & \\
\hline
\end{tabular}

Figures 


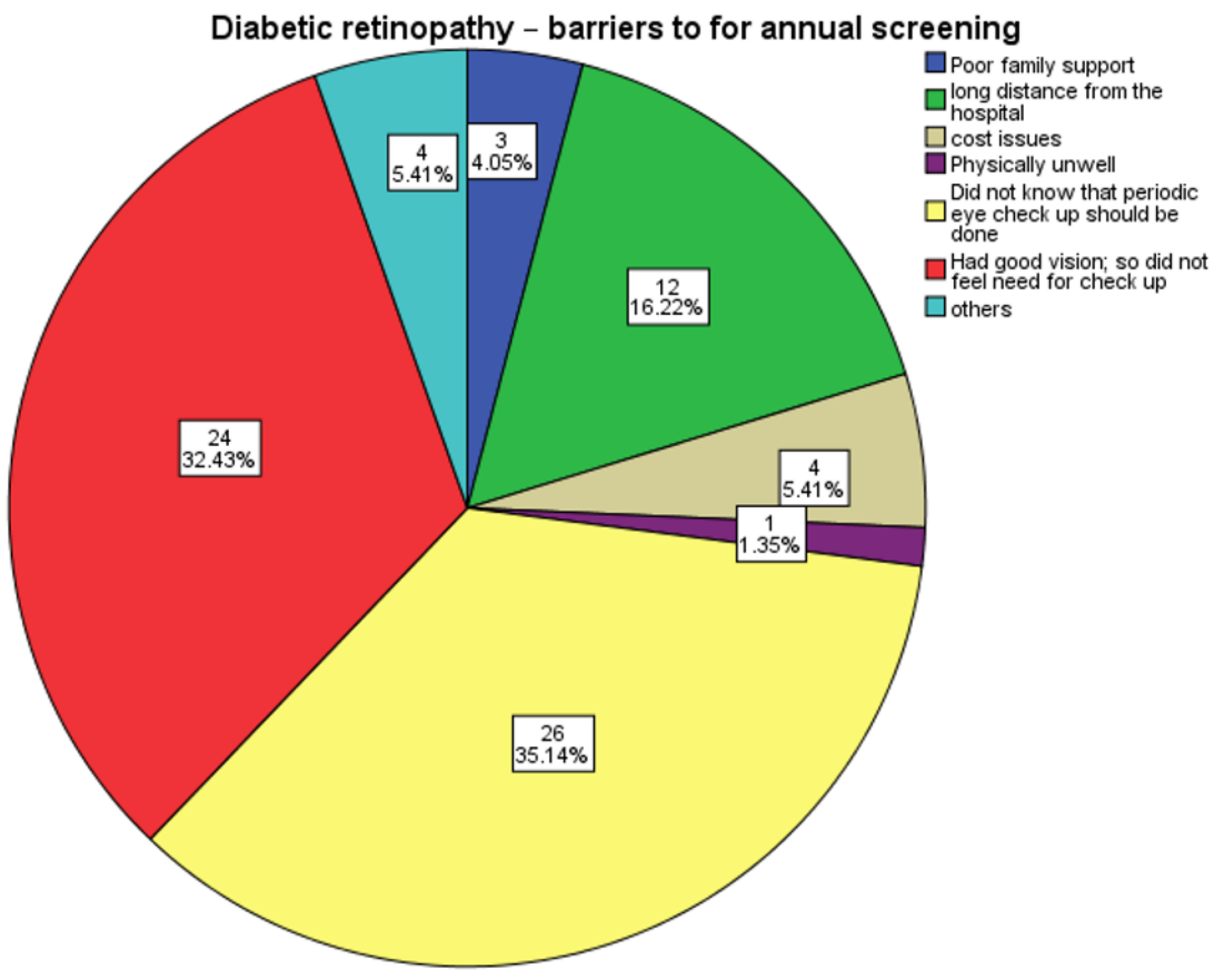

Figure 1

Diabetic retinopathy - barriers for annual screening. 